\title{
Abdominal Trauma: Five Years Experience in National Centre Hospital, Mauritania
}

\author{
A. Moulaye Idriss ${ }^{1 *}$, Y. Tfeil' ${ }^{1}$, J. S. Baba1 ${ }^{1}$, S. M. Boukhary ${ }^{2}$, B. Hamad ${ }^{2}$, M. Abdllatif ${ }^{2}$, T. A. Kane ${ }^{1}$, \\ M. Abdllahi'2, B. Moctar' ${ }^{2}$ B. Taleb ${ }^{1}$
}

${ }^{1}$ Department of Surgery, Faculty of Medicine, Nouakchott Al Aasriya University, Nouakchott, Mauritania

${ }^{2}$ General Surgery Department, National centre Hospital, Nouakchott, Mauritania

Email: ${ }^{\star}$ carcinologie@yahoo.fr

How to cite this paper: Idriss, A.M., Tfeil, Y., Baba, J.S., Boukhary, S.M., Hamad, B., Abdllatif, M., Kane, T.A., Abdllahi, M., Moctar, B. and Taleb, B. (2018) Abdominal Trauma: Five Years Experience in National Centre Hospital, Mauritania. Open Journal of Emergency Medicine, 6, 6-14. https://doi.org/10.4236/ojem.2018.61002

Received: February 8, 2018

Accepted: March 24, 2018

Published: March 27, 2018

Copyright () 2018 by authors and Scientific Research Publishing Inc. This work is licensed under the Creative Commons Attribution International License (CC BY 4.0).

http://creativecommons.org/licenses/by/4.0/

\begin{abstract}
Trauma care including abdominal trauma is a big challenge. It is associated with high morbidity and mortality and continues to be a public health problem worldwide. The main aims of our study were to assess the patterns and outcomes of our patients, and to describe our experience in management of abdominal trauma. This descriptive retrospective study was conducted in general surgery department at National Centre Hospital of Nouakchott in Mauritania. We recruited patients presented at our department with abdominal trauma (2012-2016). Out of 100 cases, $92 \%$ were men. Mean age: 22.78 years (5 - 70 years). Eighty percent of patients suffered of penetrating abdominal trauma. Stab injuries were the most frequent mechanism (60\%). The commonest organ injury was small intestine (16\%). Mortality has been strongly related to road traffic accidents. Cares of severe abdominal traumas are not common in our hospital, due to lack of required overall data. Emergency health system is needed to better care of trauma patients in Mauritania.
\end{abstract}

\section{Keywords}

Abdominal Trauma, Blunt, Stab Wounds, Laparotomy, Mauritania

\section{Introduction}

Trauma continues to be a major public health problem worldwide. Abdominal trauma (AT) is usually associated with high morbidity and mortality [1]. It may be blunt or penetrating and may involve damage to the abdominal organs. Management of AT should be approached in an organized manner, require a challenge public health among all countries, regardless of the socioeconomic status [2]. Missed or delayed diagnoses remain the most serious pitfalls in the management of abdominal injuries [3]. Most deaths resulting from abdominal 
trauma occur urgently. Penetrating abdominal trauma (PAT) typically involves the violation of the abdominal cavity by a stab wound or gunshot wound (GSW) [4]. Blunt Abdominal Trauma related to greater mortality more than PAT and more difficult to diagnose [5]. In developing countries including Mauritania, trauma in general and AT in particular are increasing due to road traffic, industrialization, civil violence and criminal activities in some areas [6]. Study reported motor vehicle crashes (MVCs), fall from height and assaults to be the most common causes of blunt abdominal trauma [7]. The penetrating trauma is mainly caused by gunshot, stab, and other objects that enter the peritoneal cavity. Mauritania is very large country located in West Africa. For about two decades, the authority has developed a road system covering almost the entire country, an increase in road accidents has been noted. But in the absence of trauma center and emergency system medical help, the majority of the seriously wounded die before, or at arriving to hospitals. Moreover, increase in incidence of occupational injuries, as well as assaults and stab injuries results in morbidity and mortality. To our knowledge, there are no publications concerning abdominal trauma in Mauritania. Penetrating abdominal trauma especially stab wound (60\%) occurs more than blunt abdominal trauma in Mauritania. In our hospital, the management of AT includes as well as expectancy and the exploratory laparotomies. After several laparotomies without identifiable injuries, Shaftan [8] suggested selective management of patients with abdominal stab wound after observing an in-creased rate of negative laparotomies. Recently several studies have favored a more conservative approach as opposed to mandatory exploratory laparotomy [9] [10].

The aim of this study was to describe our experience on the management of AT, injury characteristics and treatment outcome as seen in main single institution in Mauritania.

\section{Patients and Methods}

This retrospective descriptive study of AT patients was conducted over a period of five years (2012-2016) at the single hospital named Nouakchott National Hospital Centre which is a third level teaching hospital in Nouakchott, Mauritania.

Total of 100 files were collected. For each patient socio demographic data (age, gender and ethnicity), circumstances and mechanism, body region injured, hemodynamic status, clinical, damaged organs, length of stay at the hospital were collected. All data were entered and analyzed with Statistical Package for Social Sciences (SPSS) version 20. Quantitative variables were expressed on average while qualitative variables were expressed as a percentage. Chi-square for categorical variables and $\mathrm{P}$-value $<0.05$ was used.

\subsection{Inclusion Criteria}

We included all emergency referred patients and recorded having evidence of 
intra-abdominal visceral injury, also those with penetrating AT. Depending on the injury location, patients with extra abdominal injury were managed after an initial evaluation of the associated lesions and an agreement with the team of the specialty concerned.

\subsection{Exclusion Criteria}

All cases with death observed before or upon arrival at the emergency department were excluded.

\section{Results}

Approximately every year, more than 6000 operative procedures are performed in our hospital, a third of which were performed in visceral surgery. During the study period a total of 8926 patients operated in the General surgery department. Abdominal trauma was present in $100(1.1 \%)$ cases. There were 92 males and 8 females with a male to female ratio 11:5. The demographic characteristics and mechanism of abdominal injury are depicted in Table 1 . The age of patients ranged from 5 - 70 years (mean age: 22.78 years and median age: 20 years). The majority of patients $68(68 \%)$ presented with penetrating abdominal trauma and $32(32 \%)$ had blunt abdominal trauma. Violent activities were the prompt causes of the abdominal trauma, Stab injuries were the most frequent mechanism (Table 2), followed by road traffic accident 12 (12\%), fall from height $6(6.3 \%)$, domestic accidents $4(4 \%)$ and sports or leisure accidents 4 (4\%). In PAT the most affected anterior abdominal site (53\%) of them (26.6\%) umbilical 16 (16.6\%) epigastrium. Back sites of PAI seen in $14.3 \%$. Thoracoabdominal sites of PAT were $20 \%$, whereas only the anterior abdominal regions were affected in abdominal blunt trauma. The most common associated injury was chest (Figure 1) injuries (8\%). In Table 3, the association of type of injury with number of organs injured was significant in Chi-square with P-value: 0.002. Twenty (20\%) patients had more than one organ injured; 4patients had negative laparatomies and $14(14 \%)$ cases showed evisceration of organs. The commonest organ injury was small intestine $16(16 \%)$ followed by stomach $14(14 \%)$. On arrival to the emergency room $10(10 \%)$ patients were hemodynamically unstable with shock and had been transfused. Clinically peritoneal syndrome with tenderness was also present in $20(20 \%)$ cases. Imaging was done in $30(30 \%)$ patients. Of them 26 (26\%) were focused abdominal sonograpghies in Trauma (FAST) and revealed haemoperitoneum, Plain abdominal and chest radiographies showed two (2\%)free gas under diaphragm with suspected pneumoperitoneum and (2\%) haemothorax in associated chest injury.

Eighty four (84\%) patients were operated in emergency department, including $4(4 \%)$ negative laparotomies. Selective non operative management was realized in $16(16 \%)$ cases. Fourteen (14\%) patients require intensive care units (ICU). Mean length of hospital stay was 5.83 days (2 - 19 days). Surgical site infection was found in $10(10 \%)$ cases; and hematemesis in $2(2 \%)$ patients. The mortality 
Table 1. Patients characteristics.

\begin{tabular}{cc}
\hline Variable & N (\%) \\
Male & 92 \\
Mean age (years) & 22.78 \\
Blunt injuries & 32 \\
Penetrating injuries & 68 \\
Stab injuries & 60 \\
Road traffic accidents & 12 \\
Fall from height & 6 \\
Selective non operative management & 16 \\
Mean length of hospital stay & 5.83 \\
\hline
\end{tabular}

Table 2. Organ injury.

\begin{tabular}{cc}
\hline Injured organ & $\mathrm{N}(\%)$ \\
\hline Small intestine & $16(16 \%)$ \\
Evisceration & $14(14 \%)$ \\
Stomach & $14(14 \%)$ \\
Diaphragm & $14(14 \%)$ \\
Spleen & $10(10 \%)$ \\
Mesentery & $6(6 \%)$ \\
Colon & $6(6 \%)$ \\
Liver & $4(4 \%)$ \\
Pleura & $4(4 \%)$ \\
Duodenopancreatic & $2(2 \%)$ \\
No organ injured (negative laparotomy) & $10(10 \%)$ \\
Total & $100(100 \%)$ \\
\hline
\end{tabular}

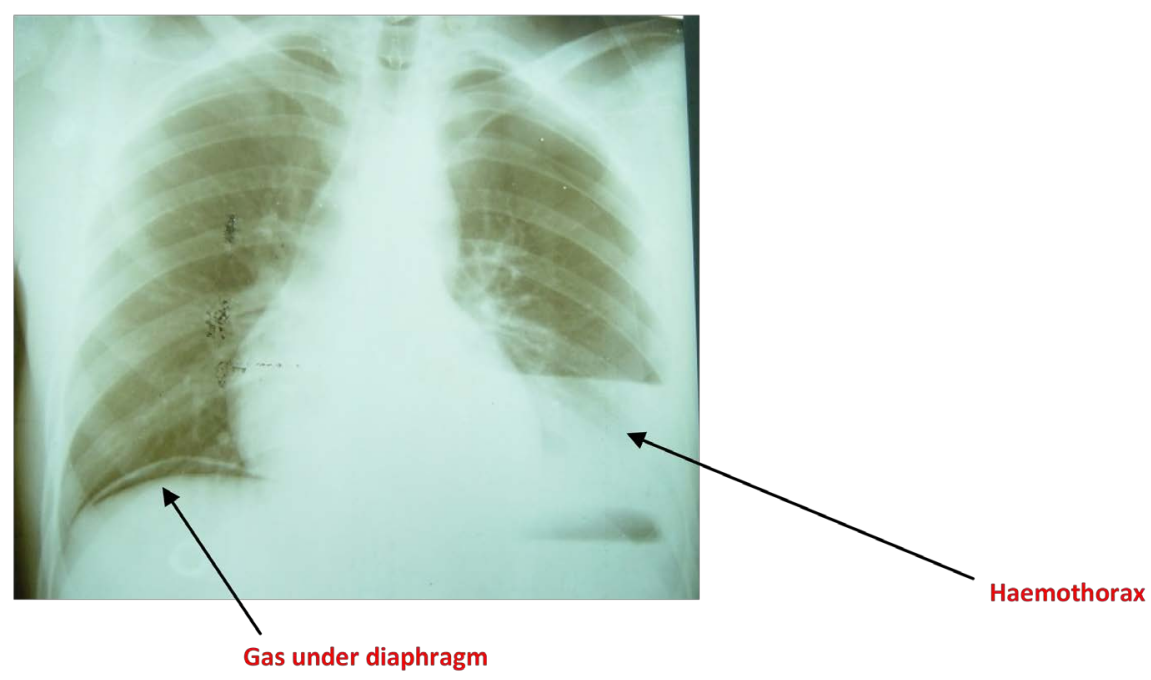

Figure 1. Penetrating abdominal injury associated chest injury (Gas under diaphragm and Haemothorax). 
Table 3. Association of type of injury with number of organs injured.

\begin{tabular}{ccccc}
\hline & & \multicolumn{2}{c}{ Number of organ injury } & \multirow{2}{*}{ Total } \\
\cline { 3 - 4 } & & One organ injured & More than one organ injured & \\
\hline \multirow{2}{*}{ Type of injury } & Penetrating injury & 18 & 50 & 68 \\
& Blunt injury & 32 & 0 & 32 \\
& 50 & 50 & 100 \\
\hline
\end{tabular}

P-value: 0.002 .

rate in this study was $2 \%$. All deaths were related to road traffic accident whereas surgical site infections were related stab injuries.

\section{Discussion}

During our research, we do not found any reports that describe the incidence and the outcome of the abdominal trauma in Mauritania. This is a descriptive retrospective study, the reasons for an underestimation of the rate of abdominal trauma are due to either unreported patients or patient who died at the site of accident or who did not reach our general surgery department. To better assess abdominal trauma the data including police records, ICU admissions and mortuary records in all centers are required. Penetrating abdominal Injuries (PAIs) in Africa constituted 30 - 66\% of the overall abdominal trauma in the accident and emergency department [10] [11]; this was slightly in agreement with our study $68 \%$. Majority of our patient were found to be young; the age of patients ranged from 5 to 70 years (median age: 20 years). The commonest age affected was 20 years, and those aged 20 to 30 years have been the most frequent victims. Our findings are consistent with recent studies from Qatar [1] and Egypt [12]. In the present study, significantly more males than females present with abdominal trauma ( $92 \%$ vs. $8 \%)$ which is consistent with Arumugam S. et al.'s report of a male to female ratio $13: 1$

Blunt injuries have been reported to predominate in many studies [1] [13] [14] but in our series no such pattern. Consistent with our results, in Africa previous studies found most abdominal injuries were caused by penetrating abdominal injuries [10] [15].

In this study stab injuries (interpersonal violence) were the most common mechanism of penetrating abdominal injuries followed by gun-shot wound. The most frequent causes of blunt trauma were road traffic accidents, followed by falls from height, this finding occurred during day-time agrees with that other study [13]. These outcomes reflect difference in early or not care of patients from motor vehicles crash. Example the patients with associated injuries had been complicated or died, usually delayed and not managed by an emergency health system which was not available in Mauritania; consequently, the interval between injury and care was too long (from hours to days) and more deeded patients were not reported. No patients were presented in the first golden hour and this had affected our outcomes. 
The anterior abdomen was the site commonly wounded in PAIs with 53\% in this study and similarly described by Maha et al. [11] and Salim et al. [16], but to lesser extend in other study [17]. PAIs thoraco-abdominal site seen in $20 \%$ of the sample we studied, this is a similar reported $20.5 \%$ by Salim et al. [16]. Penetrating abdominal injuries sites from the back region was found in $14.3 \%$ which is in agreement with other $14.5 \%$. In $2(2 \%)$ of our patients their surgery was limited only to wound exploration as there was no evidence of peritoneal penetration and this compared well to other studies [18]. As reported by other study abdomen is the third most frequently injured body part among multiple trauma patients [19]. In blunt trauma several studies reported liver to be the most common injured solid organs, followed by spleen [13] [20] [21]. However the findings of this study conform to previous studies elsewhere that confirmed that the spleen is the most common injured solid organ [6] [19] [22]. In Africa some patients have splenomegaly due to chronic infections that cause them more susceptibility to rupture with even minor trauma [22].

Gastrointestinal injuries are more frequent in penetrating abdominal injuries than blunt trauma in this study. Study [23] reported after blunt trauma, hollow viscose injuries rare and it remains the third more common injury. In the present study, the commonest organ injury was small intestine. Other studies attest to this [11] [24]. As supported by this study bowel injury are leading cause of morbidity and mortality following trauma. The presence of complications has an impact to the final outcome, all our patients with surgical site infections suffered from gastrointestinal tract injuries. In keeping with other studies [25] [26], surgical site was the most frequent postoperative complication attributing this to the fact that some of the patient had bowel injuries with heavy contamination of the peritoneum and consequently the wounds. Our complications rate was $12 \%$ which are relatively comparable to that reported by Hilderbrand F. et al. [27] where the incidence sepsis was $11.3 \%$. In contrast another study reported an incidence of sepsis following abdominal trauma of $2 \%$ [28]. Over the past decade management with better sepsis control, early recognition of the complications, early use of antibiotics and advanced ICU had improved abdominal trauma care. The overall median duration of hospital stay in the present study was 5.83 days which is lower than reported by Arumugan et al. [1] and Chalya et al. [6]. In comparison to other studies, mortality rates of $12.5 \%$ and $26 \%$ reported respectively by Musau P. et al. [29] and Mohamed AA et al. [30], overall mortality rate among abdominal trauma patients in our series was very low $2 \%$. The retrospective design and unreported patients who died was the major limitations of the present study.

\section{Conclusions}

Adequate documentation of patients and records are needed for emergency department. The reasons for rarity of severe abdominal traumas in our study are due to unreported or not recorded patients. Lack of sufficient data suggests defi- 
ciencies in our healthcare system.

Bowel injury is the commonest abdominal injury treated by laparotomy in this study and the commonest cause being stab injury. Policies need to put in place to reduce the incidence of road traffic accidents which are the commonest cause of trauma related deaths in our series.

\section{Interest Conflict}

The authors declare there were no conflict interests.

\section{References}

[1] Arumugam, S., Al-Hassani, A., El-Menyar, A., Abdelrahman, H., Parchani, A., Peralta, R., Zarour, A. and Al-Thani H. (2015) Frequency, Causes and Pattern of Abdominal Trauma: A 4-Year Descriptive Analysis. Journal of Emergencies, Trauma and Shock, 8, 193-198. https://doi.org/10.4103/0974-2700.166590

[2] Hoyert, D.L. and Xu, J.Q. (2012) Deaths: Preliminary Data for 2011. National Vital Statistics Reports, 61, 1-52.

[3] Prall, J.A., Nichols, J.S., Brennan, R., Moore, E.E., Prall, J.A., Nichols, J.S., Brennan, R. and Moore, E.E. (1994) Early Definitive Abdominal Evaluation in the Triage of Unconscious Normotensive Blunt Trauma Patients. Journal of Trauma, 37, 792-797. https://doi.org/10.1097/00005373-199411000-00014

[4] Offner, P. and All. Penetrating Abdominal Trauma. http://emedicine.medscape.com https://emedicine.medscape.com/article/2036859-overview\#showall

[5] Rosen's Emergency Medicine: Concepts and Clinical Practice, 2-Volume Set, James Adams, Google Books.

[6] Leo Chalya, P., Mabula, J., Leo Chalya, P., Mabula, J., Chalya, P.L. and Mabula, J.B. (2013) Abdominal Trauma Experience over a Two-Year Period at a Tertiary Hospital in Northwestern Tanzania: A Prospective Review of 396 Cases. Tanzania Journal of Health Research, 15, 1-13.

[7] Costa, G., Tierno, S.M., Tomassini, F., Venturini, L., Frezza, B., Cancrini, G. and Stella, F. (2010) The Epidemiology and Clinical Evaluation of Abdominal Trauma. An Analysis of a Multidisciplinary Trauma Registry. Annali Italiani di Chirurgia, 81, 95-102.

[8] Shaftan, G.W. (1960) Indications for Operation in Abdominal Trauma. American Journal of Surgery, 99, 657-664. https://doi.org/10.1016/0002-9610(60)90010-6

[9] Biffl, B. and Moore, E.E. (2010) Management Guidelines for Penetrating Abdominal Trauma. Current Opinion in Critical Care, 16, 609-617. https://doi.org/10.1097/MCC.0b013e32833f52d2

[10] Asuquo, M., Umoh, M., Nwagbara, V., et al. (2012) Penetrating Abdominal Trauma: Experience in a Teaching Hospital, Calabar, Southern Nigeria. International Journal of Clinical Medicine, 3, 426-430. https://doi.org/10.4236/ijcm.2012.35079

[11] Omer, M.Y., Hamza, A.A. and Musa, M.T. (2014) Penetrating Abdominal Injuries in Khartoum. International Journal of Clinical Medicine, 5, 18-22. https://doi.org/10.4236/ijcm.2014.51004

[12] Gad, M.A., Saber, A. and Farrag, S. (2012) Incidence, Patterns, and Factors Predicting Mortality of Abdominal Injuries in Trauma Patients. North American Journal of Medical Sciences, 4, 129-134. 
[13] Smith, J., Caldwell, E., D’Amours, S., Jalaludin, B., Sugrue, M., Smith, J., Caldwell, E., D'Amours, S., Jalaludin, B. and Sugrue, M. (2005) Abdominal Trauma: A Disease in Evolution. ANZ Journal of Surgery, 75, 790-794. https://doi.org/10.1111/j.1445-2197.2005.03524.x

[14] Haan, J. and Kerry, K. (2003) Nontherapeutic Laparotomies Revisited. The American Surgeon, 69, 562-565.

[15] Edino, S.T. (2018) Pattern of Abdominal Injuries in Aminu Kano Teaching Hospital, Kano. Niger Postgrad Med J., 10, 56-59.

[16] Salim, A. and Velmahos, G.C. (2002) When to Operate on Abdominal Gunshot Wounds. Scandinavian Journal of Surgery, 91, 62-66.

[17] Sangwan, P., Rajkumar, P.N., Quadar, A., Yaam Kumar, C. and Vivek, K. (2016) Hospital: Our Experience. International Journal of Current Research, 8, 25598-25603.

[18] Ohene-Yeboah, M., Dakubo, J.C.B., Boakye, F. and Naeeder, S.B. (2010) Penetrating Abdominal Injuries in Adults Seen at Two Teaching Hospitals in Ghana. Ghana Medical Journal, 44, 103-108.

[19] Abdelrahman, H., Ajaj, A., Atique, S., El-Menyar, A. and Al-Thani, H. (2013) Conservative Management of Major Liver Necrosis after Angioembolization in a Patient with Blunt Trauma. Case Reports in Surgery, 2013, Article ID: 954050.

[20] Clancy, T.V., Gary Maxwell, J., Covington, D.L., Brinker, C.C. and Blackman, D. (2001) A Statewide Analysis of Level I and II Trauma Centers for Patients with Major Injuries. The Journal of Trauma, 51, 346-351.

https://doi.org/10.1097/00005373-200108000-00021

[21] Matthes, G., Stengel, D., Seifert, J., Rademacher, G., Mutze, S. and Ekkernkamp, A. (2003) Blunt Liver Injuries in Polytrauma: Results from a Cohort Study with the Regular Use of Whole-Body Helical Computed Tomography. World Journal of Surgery, 27, 1124-1130. https://doi.org/10.1007/s00268-003-6981-0

[22] Ponifasio, P., Poki, H.O. and Watters, D.A. (2001) Abdominal Trauma in Urban. Papua and New Guinea Medical Journal, 44, 36-42.

[23] Wisner, D.H. and Blaisdell, F.W. (1992) Visceral Injuries. Archives of Surgery, 127, 687-693.

https://jamanetwork.com/journals/jamasurgery/article-abstract/595396?redirect=tr $\underline{\text { ue\&redirect }=\text { true }}$

[24] Feliciano, D.V., Burch, J.M., Spjut-Patrinely, V., Mattox, K.L. and Jordan, G.L. (1988) Abdominal Gunshot Wounds. An Urban Trauma Center's Experience with 300 Consecutive Patients. Annals of Surgery, 208, 362-370. https://doi.org/10.1097/00000658-198809000-00014

[25] Ayoade, B.A., Salami, B.A., Tade, A.O., Musa, A.A. and Olawoye, O.A. (2006) Abdominal Injuries in Olabisi Onabanjo University Teaching Hospital Sagamu, Nigeria. Nigerian Journal of Orthopaedics and Trauma, 5, 45-49.

[26] Nyongole, O.V., Akoko, L.O. and Njile, I.E. (2013) The Pattern of Abdominal Trauma as Seen at Muhimbili National Hospital Dar es Salaam, Tanzania. East and Central African Journal of Surgery, 18, 40-47.

[27] Hildebrand, F., Winkler, M., Griensven, M.V., Probst, C., Musahl, V., Krettek, C., et al. (2006) Blunt Abdominal Trauma Requiring Laparotomy: An Analysis of 342 Polytraumatized Patients. European Journal of Trauma, 32, 430-438. https://doi.org/10.1007/s00068-006-5065-x

[28] Osborn, T.M., Tracy, J.K., Dunne, J.R., Pasquale, M. and Napolitano, L.M. (2004) Epidemiology of Sepsis in Patients with Traumatic Injury. Critical Care Medicine, 
32, 2234-2240. https://doi.org/10.1097/01.CCM.0000145586.23276.0F

[29] Musau, P., Jani, P.G. and Owillah, F.A. (2006) Pattern and Outcome of Abdominal Injuries at Kenyatta National Hospital, Nairobi. East African Medical Journal, 83, 37-43.

[30] Mohamed, A.A., Mahran, K.M. and Zaazou, M.M. (2010) Blunt Abdominal Trauma Requiring Laparotomy in Poly-Traumatized Patients. Saudi Medical Journal, 31, 43-48. 